\title{
Design of Sandblasting Machine for Renovating Oil Barrel Based on PLC
}

\author{
Xie Junqiang, Wang Zhongmin \\ Institute of Robotics and Intelligent Equipment, Tianjin University of Technology and Education, \\ Tianjin, China \\ Corresponding author: Xie Junqiang
}

Keywords: oil barrel, renovating, sandblasting machine, PLC

\begin{abstract}
To meet the requirements of steel barrel renovation, a set of oil barrel renovation production line based on PLC is used, where sandblasting machine is a part of this production line. By using sand blasting method, it designs a sandblasting mechanism and its corresponding control system based on PLC. It automatically realizes sandblasting derusting, dust processing through the sandblasting machine. Advantages of the machine are that reducing the working strength and improving the working environment. Simulations modeling and experiments show that the design scheme is better and its renovating efficiency is high.
\end{abstract}

\section{Introduction}

In recent years, with the development of science and technology, production line is developing toward the direction of clean production, safety production, which requires that the production line system should own the characteristics of mechanical and electrical integration, intelligent, modular, network, greening and humanistic,etc. In China, according to the survey, every year there are a lot of 200L oil barrels for recycling, and the development of China oil barrel renovation equipment is very slow, the renovation method is of low efficiency, high cost, but also damaging the environment, wasting resources[1]. Therefore, in view of the existing oil barrel renovation methods for research, this paper designed a barrel renovation automatic production line mechanical structure and its control system based on PLC technology.

In this paper, the production line is divided according to its function module, there are sorting conveyor module, barrel heating module, sand blasting module, plastic testing module, polishing cleaning module, output stacking module, as shown in figure 1. In this paper, a very important module of this production line are introduced: the sand blasting module. This module is automatically sand blast to oil barrel wall after heat treatment, its aims are removing the rust and waste which residues on the surface of barrel wall. The working principle is to make the iron ore at a high speed of 54.7 degrees to the wall of the barrel, polishing through the friction between the iron sand and the wall of the barrel[2]. Impact abrasive and cutting action, changing the surface cleanliness, roughness, mechanical properties and process characteristics are the keys of abrasive machining processes[3]. This paper mainly designed this sand blasting module, its advantage are realizing the sandblasting derusting, material dust recycling, dust processing automation[4]. The 
mechanical structure is compact, it improves the efficiency of production and processing and conforms to the requirements of the safety in production, and the surface roughness of the sandblast is 25 micron[5].

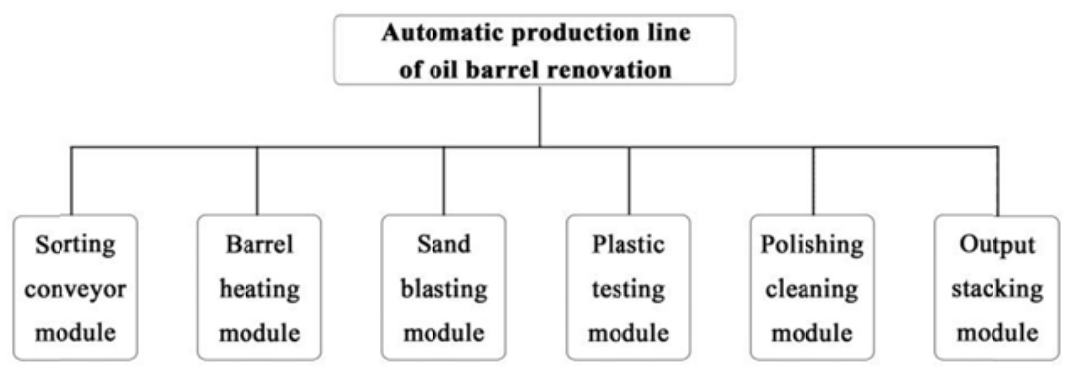

Figure 1 Partition of production line module

\section{Compositions of functional structure}

Purposes of sand blasting module are automatically sand blast to oil barrel wall after heat treatment, in order to remove the rust and waste residue on the surface of the barrel wall. Mechanical structure need to realize the delivery and rotation of the oil barrel, delivering and recycling of iron ore, sandblasting polishing action and so on. Polishing the barrel wall relies mainly on three functional structure: structure of sand supply, structure of sand blasting, structure of sand blasting room. In order to realize the function, the structure of sand supply provides iron ore sand blasting structure, the function of structure of sand blasting realizes to put the iron ore with high-speed onto barrel wall, the structure of sand blasting room realizes the function of the rotation, receiving and transmitting of the barrel. These three structures consist of a complete sand blasting module, which are shown in figure 2. Module automation control and monitoring by PLC and Wincc configuration and computer communication.

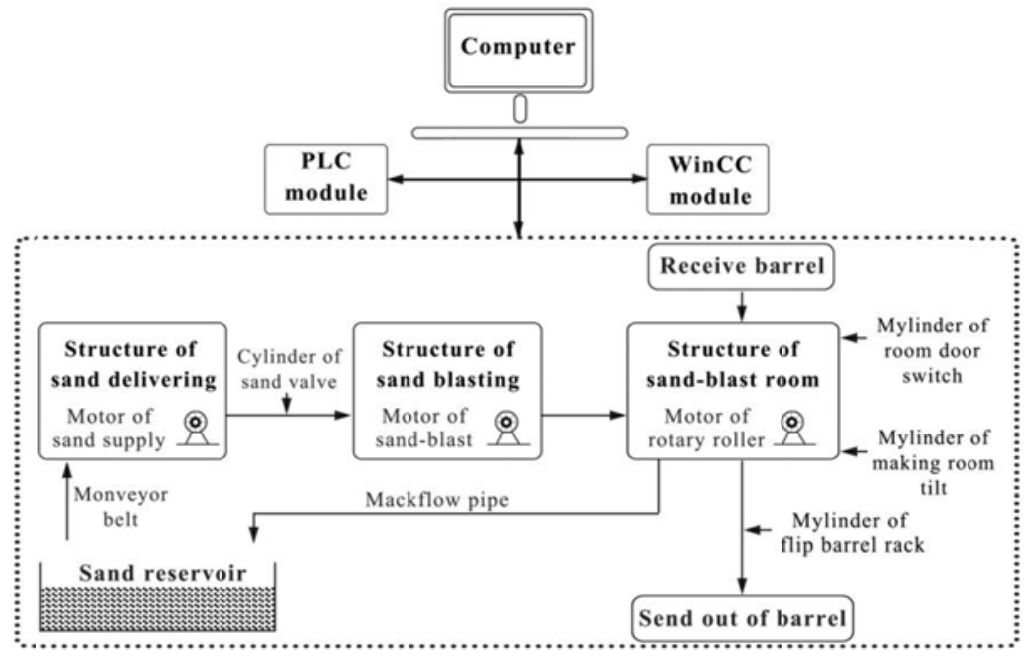

Figure 2 Composition of sand blasting mechanism

\section{Function analysis and design}

\subsection{Structure of sand supply}

The structure of sand supply is mainly composed of motor, conveyor belt, sand flow pipe and pneumatic cylinder. Its function is to supply iron ore, integrated the whole production line structure 
at the same time, diagram of mechanical structure principle are shown in figure 3 . When working, the motor drives the conveyor belt, the iron ore is taken with funnel from sand reservoir trough to sand flow pipe, motor start after three seconds interval, the cylinder of sand valve turn the sand valve on, and then the iron ore is send into funnel of sand blasting structure.

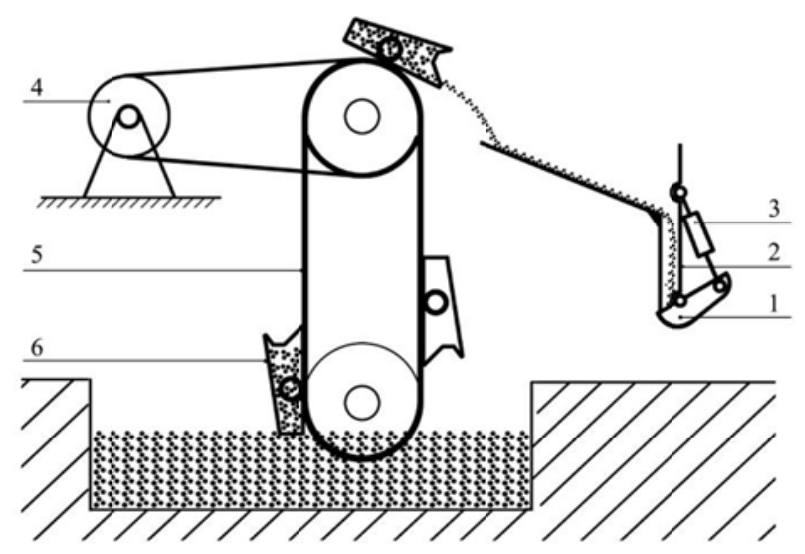

1.Switch of sand valve 2.Sand flow pipe 3.Cylinder of sand valve

4.Motor of sand supply 5 .Conveyor belt 6 .Funnel

Figure 3 Structure of sand delivering

\subsection{Structure of sand blasting}

Structure of sand blasting mainly include the funnel, structure box, sandblasting impeller, motor. The case in semi-closed, through the motor drives the sandblasting impeller high-speed rotating, then the iron ore is sprayed to the barrel wall. The diagrams of mechanical structure principles are shown in figure 4. It working procedures are described as follows, sand supply structure provides iron ore for sand blasting structure in the sand machine work with iron ore, the it opens the valve, the motor of sand-blast work at the same time, iron ore through the funnel flows into the sand box, motor drive the sand blasting high-speed rotating blades, iron ore is sprayed to the inner wall of the barrel,then sand valve is shut down after 1 minute, and the motor of sand-blast stopped working after 3 seconds. This part is the core work of the sand blasting module. Motor speed, angle of the blade and iron ore flow affects the polishing effect. Through a large number of grinding experiments, installation and debugging, it realizes the design effects.

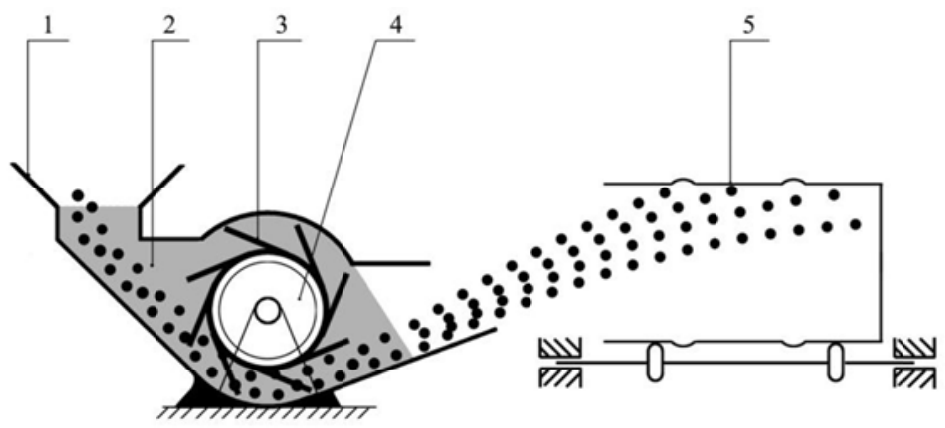

1.Funnel 2.Structure box 3.Sandblasting impeller

4.Motor of sand-blast 5.Oil barrel

Figure 4 Structure of sand blasting

\subsection{Structure of sand-blasting room}

Structure of sand blasting room achieves production line to undertake of barrel, rotation of barrel, 
it is a closed working environment. It mainly includes the flip barrel rack and cylinder, the rotary roller and motor, and a closed sandblasting room. Considering the circulating iron ore, it designs a back flow pipe. The mechanical structure principle diagram is shown in figure 5. During working, after the flip barrel rack completing undertake action, sand blasting structure begin to supply iron ore, then iron ore is sprayed to the inner wall of the barrel. At the same time, motor of rotary roller driving the roller at a constant speed to make oil barrel rotate, to make sure the evenness of iron ore to the barrel wall. After sand blasting, the cylinder of flip barrel rack work, then it turn oil barrel out.

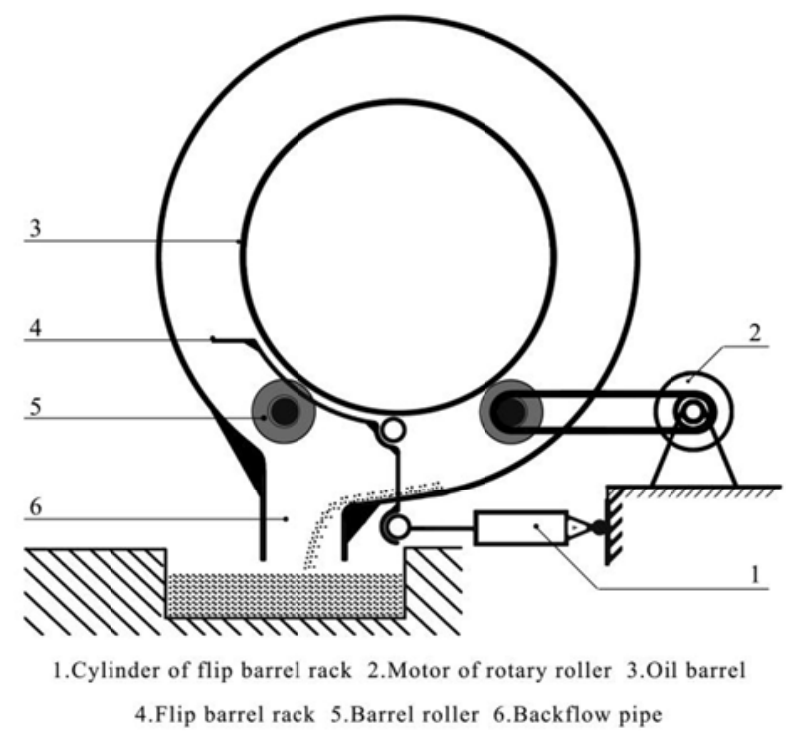

Figure 5 Sand blasting room

\section{Modeling and simulation}

Through analysis of the function of sand blasting module, in order to ensure the module implements completiing coherent barrel to undertake, sandblasting polishing, transmission, it use Solidworks software to set parameters and overall design of the module, to analyze the structure rationality, the model of blasting machine simulation are shown in figure 6 .

At work, oil barrel is transferred to sand blasting room. The cylinder of room door switch make sand-blasting room door be closed, and then cylinder of make room tilt support sand-blasting room 30 degrees. Then motor of sand supply, motor of sand-blast and motor of rotary roller begin to work. sand supply motor drive conveyor belt of sand supply structure, the iron ore was reserved in room; sand-blast motor rotation for sandblasting, rotary roller motor driving roller at a constant speed to make barrel rotate. Motors work after 3 seconds interval, then cylinder of sand valve open the switch of sand valve, sand-blast motor spray iron ore to the inner wall of the barrel. After 1 minute's polishing, sand valve cylinder work, it close the switch of sand valve. Then, after 3 seconds interval the three motors stop working. The cylinder of make room tilt work, machine back to the starting point, then the cylinder of room door switch to work, sandblasting room door is opened. The cylinder of flip barrel rack send the polished good oil barrel out. The actions time of sandblasting machine are availabled on computer screen. 


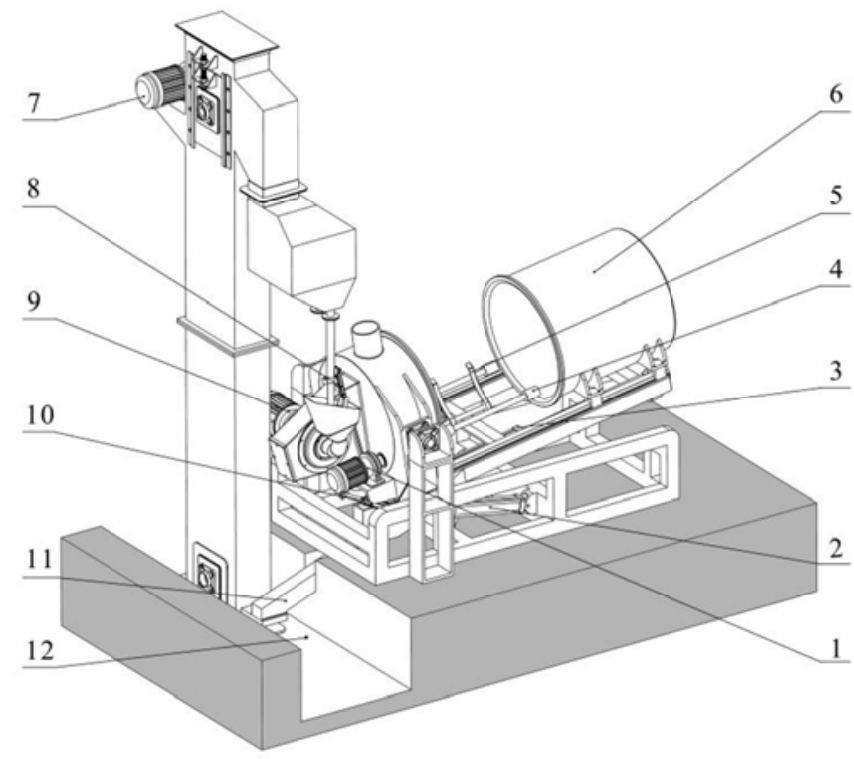

\begin{abstract}
1.Motor of rotary roller 2.Cylinder of making room tilt 3.Cylinder of room door switch
4.Rotary roller 5.Flip barrel rack 6.Sand-blast room door 7.Motor of sand supply

8.Sand valve 9.Motor of sand-blast 10.Cylinder of flip barrel rack 11.Backflow pipe

12.Sand reservoir
\end{abstract}

Figure 6 Simulation model of sandblasting machine

\title{
5. Conclusion
}

Oil barrel sandblasting machine based on PLC is designed in this paper. According to experimental results show that the roughness meet production process requirements, barrel wall surface polishing effect significantly better than the original processing technology. Through the improvements and parameters optimization, it ensures the sandblasting processing automation, simple operation, stable running and other requirements. Purpose of the barrel sandblasting machine introduced in this paper is realized and it solves the problem of dust, chemical pollution, reduce turnover in the sandblasting processing link, it improves the efficiency and feasibility.

\section{References}

[1] LIANG Suiping. Open Sandblasting Machine Technology and Environmental Transformation[J]. METALLURGICAL COLLECTIONS. 2015(4): 40-42.

[2] ZHOU Xiaojun, HAN Yanfeng, WANG Fayong. Study on the Mechanism and Parameter Optimization of Derusting by Sandblast[J], SHIP ENGINEERING, 2008, 1(30): 66-68.

[3] ZHANG Haifeng, WANG Weihua, ZHAO Ailing, etc. Research and Design of Wet Sand-Blasting Device[J], MACHINE TOOL \& HYDRAULICS, 2015, 43(10): 46-52.

[4] ZHANG Yandong, XIANG Guilin, LIU Zhiping. Design and Application of OCTG Interal Wall Blasting Machine[J]. PIPELINE TECHNIQUE \& EQUIPMENT. 2015(2): 40-42.

[5] LONG Bin, LV Xijun, TANG Deyu, etc. The Development and Application of Environmental Protection Fully Automatic Pipeline Blasting and Blasting Machine[J]. PETROLEUM ENGINEERING CONSTRUCTION. 2011(2): 36-38. 